\title{
The Social Framework of Learning via Neurodidactics
}

\section{Chournazidi Anastasia}

National Kapodistrian University, Athens, Greece

Email: achournazidi@yahoo.com

How to cite this paper: Anastasia, C. (2016). The Social Framework of Learning via Neurodidactics. Creative Education, 7, 2175-2192.

http://dx.doi.org/10.4236/ce.2016.715215

Received: August 10, 2016

Accepted: September 17, 2016

Published: September 20, 2016

Copyright (@) 2016 by author and Scientific Research Publishing Inc. This work is licensed under the Creative Commons Attribution International License (CC BY 4.0).

http://creativecommons.org/licenses/by/4.0/

\section{(c) (i) Open Access}

\begin{abstract}
Both from a pedagogical and a psychological point of view, but also from sociology, we are aware of the fact that learning is a permanently successful process, taking into consideration that learning in the school environment does not bear significant practical differences from learning in our normal, social lives. Since the 18th century already, educational theories have been developed, accepting teaching methods focusing on learning processes, in accordance with human's brain functions and aiming not for an individual, but a social aspect of learning, enhancing the individual's selfefficacy in society. Neurodidactics investigates these two parameters, in an effort to introduce brain research scientific results into courses, forging at the same time the frameworks and prerequisites used to establish knowledge that was correctly structured and integrated in a context of emotional motivation. The neurodidactics' aim is to encourage and support the management and process of learning, in a stress-free, reliable, social learning context. The following analysis of these theories should assist teachers in understanding and explaining their students' experiences and behaviors, which should always be related to the students' brain functions and physical-mental functions, as part of a learning group.
\end{abstract}

\section{Keywords}

Associative Learning, Neurodidactics, Emotion, Motivation, Memory, Socialization

\section{Introduction}

This article considers the most significant learning theories, from a teaching, psychological and sociological point of view. Learning is defined as the change brought upon an individual, as a consequence of knowledge. Learning should be expressed as a performance of knowledge and clarified as a skill and as a behavior, showcasing the aims of didactics. The factors affecting and determining the process of learning are the emo- 
tional state of the learner, motivation and memory functions. First, we present the traditional theoretical approaches for each learning factor and secondly, the neurodidactics approaches towards these factors are presented. Learning is not merely a process of memorizing knowledge to be examined and graded, but an act of communication and an enhancement of performance (Herrmann, 2008), since the educator cooperates with social-emotional individuals, ready to learn and expect rewards.

\section{Learning}

\subsection{Traditional Dependent Learning}

Looking back at the history of pedagogics and didactics, we see that the prevalent theoretical framework determining the concept of learning is that of the so-called traditional dependent learning. Traditional dependent learning is a fundamental form of associative learning, during which knowledge is learnt through the relationship between two stimuli (Horstmann \& Dreisbach, 2012: p. 13), the unconditional stimulus, which combined with a conditional stimulus (signal) evokes the conditional response to the learner. The theoretical background of traditional dependent learning is based on the observations of scientist Iwan Petrowitsch Pawlow, whose experiments are based on traditional dependence; in other words, adapted reaction and the acquisition phase.

Some of the supporters and practitioners of traditional dependent learning include Kamin (1969) who proposed that the combination, this affinity between stimulus and reaction, is not sufficient for associative learning, but the conditional stimulus should provide information and be unexpected. His theory is known as the Blocking-Effect theory, according to which, the conditional stimulus and unconditional stimulus with no informative relationship to each other, are ignored by the learner and lead to blocked association.

Another advocate of the traditional dependent learning is Seligman (1970), whose Preparedness assumption theory is based on the individual's congenital willingness for learning. An individual is ready for the associative process.

The most complete model of traditional dependence is the one suggested by Recorla \& Wagner (1972), according to which the unexpected element is substantial for learning. If the connection between stimuli is predictable, learning cannot exist.

The starting point for evaluative conditioning is an experiment performed by Levey and Martin (1975) that studied the power of positive and negative images and included the individual's critical thinking towards cognitive objects. A similar method employing words was used by Fazio (2001), who introduced the affective Priming example, in which a word is examined to conclude whether it evokes positive or negative connotations.

A different turn in the traditional conditioning theory was taken by Thomdike's observation regarding free, variable reactions to stimuli. Thomdike is known for the effect law, based on the satisfaction brought upon by the connection between state and reaction. A satisfactory reaction signifies aiming and retention of knowledge, hence a successful learning process. On the other hand, aversive, is the state in which we are trying 
to avoid something or stop, hence we have an unsuccessful learning process.

Instrumentally or operant learning is differentiated from the traditional conditioning learning, since it does not limit itself to the learner's simple reaction, according to Skinner (1963), but expands in the effects of this behavior to the surroundings. Factors considered in this theoretical framework of learning include the possibility or frequency of a behavior, following a random reinforcement, which can be a positive reinforcement (e.g. praise) or negative reinforcement (removal of an unpleasant stimulus). The consequence of negative reinforcement is avoidance or helplessness. This learning style aim is shaping, an arrangement of a behavior towards the desirable direction, which is none other than a change in behavioral dynamics, i.e. a reduction of a possible problematic behavior. We should state that according to most researchers, punishment merely displaces and does not eradicate an unwanted behavior. According to its advocators, in order for a punishment to be effective (Azrin \& Holz, 1966), the punishment stimuli should be intensive, punishment should be enforced immediately and most importantly, it should provide the perspective of an alternative behavior. But since punishment decelerates the progress of learning and leads to emotions of fear or shock, the instructor should instead focus on reinforcement. Premack (1963) in particular, a theorist of learning, suggests the equation of reinforcement and behavior.

Finally, observation learning focuses on imitative behavior, that is, the connection between perception and performance, using a common coding (Prinz, 2005). Observation clarifies the affinity between the imitating act (based on a model) and the outcome, which leads to knowledge. Learning theory based on observation, mainly supported by Bandura (1976), suggests that traditional dependent learning is focused on individual learning. Observation is based on learning within a social framework. Attention focusing, memory, motivation and reproduction are the stages of learning based on observation.

\subsection{Neurodidactics}

Neurodidactics is a modifying method of teaching and learning. In combination with biological psychology and social psychology, it focuses on the learning states supporting brain functions. Let's take a closer look at how the brain works.

Our brain is a mass consisting of several small cells called neurons. Neurons continue to form well into adulthood, but several of them are also destroyed through our lifespan. The temporal point and magnitude of these changes depend on maturation processes and stimuli from our environment. Each neuron has dendrites, receiving chemical and electrical signals from adjacent cells and forwarding them to the neurons. This mission is accomplished by axons, surrounded by a substance similar to an insulating layer, called myelin. A neuron with strong myelin forwards information is faster, while a neuron with low insulation works more slowly. The quality of myelin, connections between neurons and the development of synapses, define our abilities, connect information we receive and forward signals to different pathways. It is evident that the above process is of particular significance for the process of learning and human beha- 
vior. Bailey (2001) defines a developmental stage of human, the so-called learning susceptible stage, as a critical window of time. If stimuli expected by the brain are absent during this stage, then the contact points of neurons are disrupted. During this time, the child acquires, develops and completes all the capacities and skills related to life in a cultural frame. The brain region in which these skills develop is the frontal lobe. This part of the brain is the last and the slowest to reach maturity. But it is the very part that defines future plans, internal directions, develops the sense of responsibility and emotion sharing with others. Thus, the frontal lobe is structured through the process called education, which is absolutely at par with socialization. Here we notice the interdependent relationship between brain development and the development of behavior, thinking, emotions and memory. Interaction with other individuals completes the brain's synaptic networks, since experiences activate new neuronal connections. These represent within brain, events from the outside world in a symbolic manner (Hüther, 2009: p. 45).

The aim of pedagogics according to neurodidactics could be its study, the discovery of stimuli, encouragement, abatement and rules reinforcing a child's learning-susceptible stage and the information that are important to concentrate brain processing on these.

\section{Emotion}

\subsection{Emotion Theories}

Emotion theories, which we shall analyze further blow, focus on the interaction between emotion and knowledge. The term "emotion" refers to the mental states addressed towards a particular object, that is, having a reference point and manifesting not only on behavioral dynamics, but also on the dynamics of the individual's experiences.

The main advocate of physiological theories is James (1884), who interpreted emotion as a perception of emotional physical reactions. This is a consciously perceived, physical impulse, registered at an individual's sensory cortex. Every time this impulse is induced, it is brought upon by the entire state, e.g. the sensation or experience of risk, overwhelming the individual. Cannon (1927) developed a central-nervous theory about emotion, where the hypothalamus leads emotional reactions and the thalamus convers these emotions into knowledge.

Damasio (1994) showed interest not on emotions per se, but the decision making behavior. According to this theorist, decisions are made when possible affective consequences become anticipated. Damasio's theory, known as somatic markers, bases affective anticipations, which are mostly physical reactions, to previous experiences witnessed by the individual in similar conditions. These reactions are stored in the brain as markers.

Behavioral theories deal with the emotional behavior in particular and how emotional behavior changes through learning. A core method is direct conditioning, based on learning according to a model. An advocate of these theories was Jones (1924), known as the mother of behavioral therapy, in which a negative stimulus, e.g. fear, is repeti- 
tively combined with a positive stimulus, in order to evoke the opposite unconditional response, thus a desensitization.

Developmental theories about emotion are based on instinct and Charles Darwin's theory of evolution. An individual's optimal adjustment is influenced by artificial selection (pressure exercised for education) and natural selection (pressure exercised for learning). According to evolutionary theorists, genes structure and maintain an individual in his/her pursuit and/or opposition with his/her surroundings. But behavior is not determined by genes, but rather by the nervous system, which consists of mechanisms accumulated into a module. According to theorists Cosmides \& Tooby (2000), modules are created by selection pressures. Each module operates independently, receives a specific input and produces a specific output of information (Fodor, 1983) in order to deal with a particular adaptive problem (challenge by the physical and social environment). In evolutionary psychology, modules are emotions, leading body and spirit in the resolution of an adaptive problem.

An advocate of emotional imitation or neuron-culture theory was Ekman (1972), who studied the way in which an emotion automatically stimulates an individual's imitating action (expression of emotion) and how it is expressed in the cultural framework in which the individual finds itself and which uses display rules to specify the imitating behavior. Fridlund (1991) on the other hand stated that imitating behavior does not serve communication, but serves for people to influence the behavior of other individuals, in an effort to regulate social conditions and in our case, the conditions of learning society.

Appraisal theories or cognitive-evaluative theories of emotion, developed during the 60 s, are a series of appraisals regarding magnitudes, opportunities etc. directly linked to emotions, caused by the effect an event had on the individual. According to Arnold (1960: p. 174) these are clearly sensual, "direct, immediate, not intellectually [but] automatically" provided appraisals. The main advocate of these theories is Lazarus (1991) who focuses on two appraisals. It is first the appraisal of the situation (relevance of knowledge aim, congruence with the aim and participation of ego in the learning process) and secondly the appraisal of coping abilities (profit or loss, coping dynamics and expectation of future changes). The aim of these theories is to structure emotions. The most known of models based on this theory is the cognitive OCC-Model by Ortony (1988) and his colleagues. This model depicts the appraisal reaction of an individual towards an incident and studies the following parameters: the appealingness of an object, the individual's emotional state (desirability) and the scope of his/her expectations (hope or fear), the implications the incident may have on others (favor or disfavor) and the acts of agents (praise or reproach).

Dimensional theories of emotion, mostly investigated by Russell (1991), categorize emotions. In dimensional theories, emotions are interpreted as prototypical emotional incidents, which form a group of complex elements, such as the object with which the emotional incident is related, the proper behavior, attention, knowledge and appraisals towards the object, the experience itself, physical changes and mostly basic affect re- 
lated to the fundamental, consciously accessible emotional state (disposition, adjustment etc.). Theorists like Russell, separate emotions in two aspects (disposition and irritation) or three aspects, such as Wundt (1922) (disposition and non-disposition, irritation and relaxation, intensity and resolution) or according to Lang (2008) (valence, irritation, dominance).

Finally, we shall refer to interaction between knowledge and emotion, that is, the way emotions affect our thinking and our acts. This relationship includes the activation and action of memory. According to theorists of interaction between knowledge and emotion, emotions affect the kind of information an individual prefers to recall in his/her memory and process. A positive emotional state promotes positive thoughts and memories. But our memory is linked to emotion. This is very important for learning, since if the emotional state during learning is the same with that during the recollection of taught knowledge, memory can function unhindered. Brown \& Kulik (1977) systematically studied emotional content of memory and attempted to describe them using the term flashbulb memory, a term depicting the accuracy and attention to detail provided by memories. Isen (1999) proved through her experiments that positive affects entail increased creativity, increased flexibility and increased willingness towards new situations or experiences. A positive affect can be considered as a signal for the lack of hazard, and thus reinforce a more open and perhaps riskier behavior, while a negative affect may signal hazard and lead to a more careful and less flexible behavior (Horstmann \& Dreisbach, 2012: p. 95). On the other hand, it has been documented that even negative affects may lead to creativity, particularly when through repeated errors we realize that we need to change the resolution direction we have chosen.

\subsection{Neuron Theory of Emotion}

The following theoretical approaches are neuron-scientific, and as denoted by their name, they approach emotions from a neuronal starting point. Neuron-scientists study the emotional statuses which within a learning framework enhance learning and the emotions leading to learning avoidance. Advocates of the theory include James (1884), who sought the interpretation of emotions in somatic-sensory reactions and Cannon (1927) who focused on brain regions (amygdala and cortex). The most known theory on the role amygdala plays was developed by LeDoux (1998) who linked it to the emotion of fear. According to LeDoux, amygdala is the structure in which information is carried via afferents and this is the region in which fear-combined changes of experiences, behavior and physiology occur (efferents). According to other theorists, this is a state of alert form.

In the neuron-centered theoretical framework, brain is perceived as a "social organ", constantly seeking for cooperation, relationships that carry it forward, a friendly and relaxed state that inspires trust, and not fear of failure or faults, since trust enhances creativity. These characteristics make learning attractive and enhance personal willingness towards it. Rewarding and fun in team work, are more important than performance. This is the goal of neuro-didactic education. Social-emotional relationships 
within a learning community are necessary and the establishment of such relationships is the core of learning. Participants in such an environment are not merely brains storing knowledge, expected to operate at identical levels, but independent brains producing knowledge, assessing information and forming notional relationships (Hermann, 2008: pp. 14-15).

We understand that the environment influences and modifies our brain's neuronal architecture. Neuron cells are constantly creating new connecting bonds among them, according to our actions and experiences. This is why we refer to the brain's neuron plasticity and mirror neurons, reflecting our relationships with our surroundings. In particular, and from a neuro-biological point of view, the feedback for our body state is registered in the somatic-sensitive cerebral cortex, and our self-esteem and emotional state in general are registered in the Anteriorer Gyrus Cinguli brain region. Mirror neurons lead our experiences and behavior. When for instance we watch another individual perform a task, we also perform it intuitively. Mirror neurons react on their own and silently, with an internalized knowledge of the significance of the action we are watching. This takes place not only when we are watching someone else, but also when we perceive another individual's emotions. Mirror neurons favor imitation, that is, the unconscious and impulsive tendency to imitate what we see. They allow us to communicate and find a mutual, social agreement and form the neuron-biological foundation for learning according to one model (Bauer, 2009: p. 54).

A student's brain develops very quickly in correlation with school learning and expectations for rewards. This proves willingness for learning, which is reinforced when the student perceives it as a positive endeavor (Roth, 2009: p. 65). Intense stress, in combination with fear of failure and a sense of threat, lead to learning inhibition (Roth, 2003). The emotional state that should be established is that of empathy, social interaction and impulse control. Such a learning social environment can favor willingness for learning and ensure learning success. Within the team, learning takes place as a trial and as an experiment, a fixed process without individual modifications (such as boredom, stress, indisposition) but with temporal modifications of intensity (information acquisition) and intensity release (establishment of information). These modifications support brain functions and help avoid stress, which acts by inhibiting the brain.

\section{Motivation}

\subsection{Theories of Motivation}

Motivation psychology deals with the needs, motivation, desires and intentions as the causes of actions. The first theorist we shall mention is Heider (1975) who worked on naive psychology. According to him, any changes on an individual are a sum of effects of the individual itself (motivation and capacity) and his/her environment (difficulties and coincidences). The result of an action forms this exact sum.

Freud developed the drive theory. Drive is a constant force, only to be tamed with the satisfaction of the cause (need). The impulse is not freely developed, but instead follows specific pathways. The impulse snub is limited by the demands of reality, norms and 
values, as well as defense mechanisms (when the satisfaction of an urge is not acceptable by society, the individual activates mechanisms which displace and divert the urge to e.g. sublimation) and causes an action as an act or thought. The most known drive theory was suggested by Hull (1943) and is a learning-focused theory. Learning is a habit, reinforced and guided by the learning process. Without drive, this behavior cannot be activated; however, drive cannot guide it either. The satisfaction of a need reduces drive and thanks to this reduction, we are guided to learning. In addition, it is worth mentioning fear as drive, a suggestion investigated by Spence (1958) and Miller (1956). Fear increases drive. This is an unconditional response to an aversive situation, such as shock.

Lewin (1964) is an advocate of the field theory, according to which, the subjective perception of a situation is essential for the individual's mental status. A fundamental concept in his theory is intensity, since intensity is a dynamic figure and as such, incites the individual to act, in our case, the act of learning. The creation of an intense mental situation causes the desire for knowledge. The individual is allured by the object of knowledge, by the event of teaching. Knowledge as an object and teaching as an event, acquire the traits of a request. Such request traits act as field forces, influencing mental procedures and leading to the act of learning, which corresponds to the satisfaction of desire and thus a balanced state for the individual. Field theory supports the simultaneous existence of different field forces. In other words, different intentions, different aims-knowledge, may acquire request traits, i.e. valence. When these forces are equal but towards different directions (approach or avoidance of the object of desire, that is, knowledge) we are led to a conflict. Should the individual decide to avoid the conflict, he/she abandons the field or finds positive traits within the conflict, e.g. prospects for happiness, which lead the individual to overcoming obstacles-forces.

Now we shall consider the theories based on structural concepts, focusing on the selection of actions. The first such theory is the decision making theory. According to this, our decisions are made under an emotion of uncertainty. They are risk-carrying choices. For this reason, the individual sees and expects from the object of knowledge, a certain benefit, a value, striving to increase the possibility of winning this benefit (subjective expected utility). We choose the alternative which closely corresponds to the subjective expected utility. The second theory is the prospect theory, focusing on cases where the subjective appraisal of benefit and loss, does not correspond to the objective value and actual possibilities. In this group of theories, we find the risk-selection model of performance motivation. We first examine Atkinson's (1964) theory, which attempts to anticipate and explain an individual's decision, in the framework of performance. In his theory, Atkinson took into consideration the inter-individual differences in evaluating success and failure. This evaluation is determined by the intrinsic impulses of success and failure, in other words, the experience of pride and shame. The attractiveness of choices does not only depend on the subjective and objective value of goods, but also on the attractiveness of acquiring them. Murray (1938) focuses on performance acts, suggesting a high need for achievement. We see learning processes as acts of per- 
formance, aiming to achieve a difficult goal, such as overcoming obstacles, dominating over others, exceeding our own self and others etc. The individual's behavior in such cases consists of intense a repeated effort, focusing on a higher goal, decisiveness, power of will etc.

Cognitive theories do not focus on the affective gain (pride), but on the cognitive one (value of information). According to these theories, we select missions which correspond to our skills. Hoppe (1931) worked on the level of demand placed by the individual itself, with regard to his/her future performance and the fluctuations of this level within time. An important role here is played by previous performance and its outcomes. The difference found is called aim discrepancy. In learning, the individual makes repeated efforts within a cycle consisting of the following stages: prerequisite of demand, effort for performance and appraisal of the outcome as a success or failure. If the mission is perceived as dependent on coincidence, the individual shows preference for easier missions and greater chances of success.

Now we shall consider the attributional theories of motivation. These theories focus on how the perceived causes of actions influence expectations and the selection and performance of actions. Motivation is very important here and it is the pursuit of acquiring knowledge for ourselves and our surroundings, in order to make an influence and cause changes. This is achievable, since human uses casual attribution to relate the outcomes of his/her actions. These casual attributions are categorized to casual dimensions, according to Weiner (1980): individual-dependency (effort, skills), stability of cause and skills and the control exercised by the individual on what is perceived as a cause. Kuhl \& Goschke (1994) made a differentiation between motivational processes regarding the placement of a goal, and volitional processes regarding the achievement of this goal. This differentiation is evident in the Rubikon Model by Heckhausen \& Gollwälzer (1987). According to this model, when setting a goal, we initiate certain strategies of selection during the planning stage, which we perform during the execution stage. In the completion stage, which is also the evaluation stage, we compare the outcome of our action with the goal set. When the individual weighs the positive and negative consequences of alternative goals, he/she is led to the decision, which is called inclination towards the outcome. Thus the individual is found in a conscious state, oriented towards reality, developing his/her self-commitment towards the achievement of the goal (Horstmann \& Dreisbach, 2012: p. 139). Kuhl suggests strategies to control actions for the goal achievement: controlling the surroundings, controlling attention, controlling encoding, controlling motivation and emotion, financial processing of information and overcoming failure.

Finally, we shall consider intention theories. Gollwitzer (1999) investigated the issue of what we should do in order to achieve an intention practically and concluded that the prospects of success towards the goal achievement, first and foremost depend on the specific formulation of the goal. He makes a differentiation between goal intentions and implementation intentions. Intentions are very significant, since experiments performed have proven that individuals with specific implementation intentions, com- 
pleted missions more frequently. Also, the possibility of achieving a goal was increased in individuals with goal intentions. Under favorable conditions, intentions can automatically activate intentional associative behavior (Horstmann \& Dreisbach, 2012: p. 143). In emergency conditions, the step of action is implemented, based on implementation intentions.

\subsection{Motivation in Neurodidactics}

In neurodidactics, a substantial motivation is the student's curiosity for learning. The student's attention is focused, when his/her curiosity is aroused. This is achieved via unexpected news, unexpected events which require explanation (Hermann, 2008: p. 11). The sense of curiosity is directly linked to the behavior exhibited during the learning game within the social group of learning. Learning in the form of a game, causes improved perceptional abilities and experimentation with social roles. A child learns not passively, via ready knowledge, but by actively investigating the unknown. The room becomes a field of experimentation and innovation, replacing the teacher-centered instruction. Sachser (2009: pp. 21-22) suggests that the learning area should be a "relaxed field", offering impulses and a sense of security. There should be structures offering security. For neuroscientists, an enriched environment is very important to support learning behavior, rather than an impoverished environment, since it activates a brain area (hippocampus) and the physiological systems (sympatical-adrenal gland) related to the learning behavior. Interaction between the above and the environment, mechanisms of interaction, guide the learning behavior and the learner develops strategies to resolve difficulties.

The inclination for learning is satisfied, when we relate what we have learnt with what we can discover in the world. New knowledge is correlated with what we already know and can do the familiar. Thus, trust is activated in the brain and the child feels free among new information. Otherwise, fear, pressure and discomfort are caused in the brain. New knowledge are not correlated to stored memories, no new knowledge is added which can be stored and established in the brain to be used later on, and confusion is prevalent. As a result, behaviors including attack, defense or withdrawal are adopted. The child loses the joy of curiosity, feels weak and reacts with anger or disappointment. The emotion of trust is that which dissipates confusion, unblocks brain functions, retaining them open for learning and the discovery of the child's skills. Trust is directed towards the individuals of the environment and the notion that participation and presence in learning is meaningful, that emotion should belong in the learning world. The child can respond to demands, offers and expectations, with the help of guidance, provided by role models. Role models help stabilize in the child's brain his/her own internal self-efficacy and self-motivation during the process of learning. Roth (2003) discovered that credibility is a basic factor in interpersonal relationships and thus in the learning society. The student can understand whether the teacher is motivated, familiar with the material taught and in agreement with what he/she is teaching.

The learning social environment should practically document the value of knowledge 
and offer the child the opportunity to actively participate in the arrangement of the learning world. Children should not be forced to become passive recipients of the learning material and means, they should be provided with the freedom of discovering and creating and allowed the room to think and resolve a problem. Attention should also be provided to each child's specific needs and desires, and above all, the child should be rewarded. The brain is always open for learning and is first and foremost willing to respond and become oriented in the world, not just memorize knowledge.

\section{Memory}

\subsection{Theories of Memory}

In this chapter we shall consider various concepts and models of memory. We shall examine the factors affecting successful learning and why forgetting is useful. Memory is a sequence of three processes: encoding (acquisition of information), storage (constant mental representation of information) and recall (successful detection of stored information). The Atkinson and Shiffrin (1968) model provides an exhibitive description of memory foundations. We shall examine this model. Memory control processes, with regard to information, are rehearsal, chunking and elaboration. These controlling processes determine the sensory register (visual, auditory), where insignificant information is easily forgotten. Information on which we focus, reaches the short-term memory, where it causes a proactive interference (previous knowledge disrupt the storage of new information) and retroactive interference (new information disrupt access to already stored information). Information stored and recalled, reach the long-term memory. We should mention here that the existence of visual memory (sensory memory for visual information) was proven by Sperling (1960). Visual memory is a connecting link between perception and memory and can acquire several pieces of information within a short amount of time. Short-term memory acquires explicit dispatches, instantly queried. According to Atkinson and Shiffrin, information is carried from the sensory to the short-term memory, when we focus our attention to it. Information is retained only for a few seconds in the short-term memory, but it can be retained longer, via rehearsal (internal repetition). Rehearsal is an ability that allows us to handle the limited capacity of short-term memory. Personal capacity (chunking) of forming chunks (content with significance) largely depends on preexisting knowledge, and thus, the long-term memory.

Now we shall focus on the encode processes, the processes related to transferal to the long-term memory. Information which is retained for an ample amount of time in the short-term memory, manages to automatically enter the long-term memory. Time is not sufficient on its own, but level of processing is also important, determining the memory delivery quality. According to Morris (1997) an important part in this point is also played by the transfer-adequate processing between the encoding and recalls states. In other words, the more similar these processes are, the better the delivery of memory. Other factors positively contributing to the process are the organization of learning material and automatic generation of memory content. Slamecka and Graf (1978) have 
proven through research that cases of identifying words we generated on our own, have better outcomes in comparison to words we simply read, with regard to memory. This means that the material we generate ourselves, is better established in our memory, in relation to material we have passively acquired. A deeper processing (elaboration) enhances the understanding of the material and provides for its better establishment in the long-term memory, when combined with preexisting knowledge and exercises encouraging active interaction with material, and not mere comprehension.

A particular conceptualization of short-term memory is the working memory. Researchers Baddeley \& Hitch (1974) challenged the operation of short-term memory as simple information storage, and concluded that it is a working memory. Short-term memory's core and actual operation is to retain, modify and update information, new ones or those stored in the long-term memory, allowing the exchange of information between different activities. The working memory model consists of two components, the visual-spatial sketchpad (for visual and spatial information) and the phonological loop (for lingual information). Baddeley expanded the model, adding the episodic buffer, with multiple aspects and related to the long-term memory. This idea allows the learning of a foreign language and the learning of visual-spatial knowledge about the world. When we read, we activate the visual-spatial sketchpad. When we use our thinking to repeat what we have read, we need the phonological loop. The central executive coordinates exchange of information between these two systems. Lingual information transiently remains in memory, thanks to the phonological loop. Auditory information has simultaneous direct access to the phonological memory, while visual information (e.g. reading) may be transferred to phonological code, in order to acquire access to the phonological memory. Without the rehearsal, this information is lost.

Finally, we shall consider forgetting. Certainly, the ability and skill of recalling previous experiences help us avoid making the same mistakes in the present and future. But our ability to forget protects our cognitive system from being overloaded with useless information. Of course, forgetting does not only depend on time. The permanent characteristics of the process of forgetting are the following: decay (the passive eradication of traits of memory with the passing of time. This takes place when between encoding and recall, the activities that would lead to interference do not take place), retroactive interference (forgetting here is a consequences of processes performed simultaneously and affecting the consolidation process, thus having traits of memory not well-stored being disrupted by new information), dysfunctional guidelines for recall (here forgetting means that there is a weak association between the memory content and the recall guideline), inexistent recall guidelines (traits of memory for events we consider to have been forgotten, are suddenly recalled), retrieval induced inhibition (an active inhibition process of information, which is not required at a certain point in time. This is a transient dislocation of information, but its trait is never dissolved or destroyed), motivation forgetting. Forgetting is considered to be an erroneous delivery. Schacter (2003) discerns different omissions, that is, absent memories (Transience = reduced access to memory with the passing of time; Absent-mindedness = carelessness 
during encoding; Blocking = the information is stored, but at that given time the individual cannot recall it) and commissions, that is, erroneous memories (Misattribution $=$ memory content listed under erroneous sources; Suggestibility = memory content for events that did not take place; Bias = current memory distorting past memories; Persistence $=$ involuntary memory intrusions, which we cannot forget).

\subsection{Memory in Neurodidactics}

According to the traditional didactics and methods, learning is an instruction, that is, a processing and storage of knowledge provided. For neurodidactics, knowledge, not so much as an object but with regard to its significance, cannot be transferred. It can only be created anew within the brain of each student. Knowledge assimilation is performed unconsciously and is based on prerequisites framing learning (Roth, 2009: p. 58). Each word and sentence acquires the identity of an event and is compared with the contents of lingual memory, that is, already existing knowledge carrying a semantic meaning are activated. The proper existing knowledge is recalled, related to new knowledge and thus creates new knowledge networks. Learning is an active process of meaning production (Roth, 2009: p. 64). Memory performance which is strong (for instance, spatial orientation or visual imagination) should be linked to weak memory performance (e.g. number memory). A teacher should be very familiar with the student's type of learning and memory, in order to apply the correct method in the school context. That is, he/she should present material with amendments, both lingual and visual. In such a learning framework, cognitive meaning is formed in the brain, and in particular in the limbic system, to which also transferred are affects, motivations, emotions and is, in a way, a controller of learning success. Here is the main evaluation system of our brain and if what is happening to us is good, beneficial and pleasant, thus it should be repeated. These evaluations are registered in the emotional experiential memory.

Knowledge memory consists of several modules which may work independently, but are interrelated (Markowitsch, 2002). These modules are used to store various aspects of a content taught (individuals, facts, objects, places, names, new information, etc.) but these different aspects form a uniform semantic field. The greater the number of memory modules in which a material content is stored, the better the memory performance is, since recalling a certain aspect, enhances recollection of other aspects and finally the entire knowledge content (Roth, 2009: p. 66). This is why it helps presenting information descriptively and in direct relation to daily living, in order for children to be able to use their imagination. This does not simply make a lesson more fun, but it increases the potential of connecting other new content with already existing one. If there are interwoven memory networks, each new element of content is quickly established and recalled. A lesson which is based on variety rejects memorization, in which memory networks are formed via mere repetition of content. Memorization always works when there is no interest for learning or preexisting knowledge. Thus, memorization promotes implicit learning, instead of semantic, in which the student enters the learning material and associates his/her own knowledge. 
Information to which we pay attention and which we process, reaches the long-term memory. Transfer of information from the short-term to the long-term memory, is not a passive process. Information we learn, is abundant of associations to already stored sections in our memory. This takes place in the working memory, in which information is actively retained and controlled. The working memory may be limited in capacity, but a categorization or compaction of isolated information into clusters, can facilitate and lessen memory requirements. Long-term memory is unlimited, with regard to time and amount of memory sections (Markowitsch, 2005). This memory consists of different kinds of content processing, which, through the process of learning in a class, are connected in a single whole: 1) episodic memory, the content of which is autobiographical, that is, it refers to the individual itself and is emotionally evaluated, but according to the experiences stored, it can serve an anticipation for future actions (Tulving, 2002). 2) The deepest system is the semantic memory, which is also called a knowledge system. The greatest part of our knowledge is stored in the semantic memory, if at the same time the temporal-spatial context of the information acquisition is stored; that is, the framework of learning and the associated emotions. 3) Our perceptive memory allows us to identify objects, faces, sounds or other impulses, according to the emotion of familiarity and trust. 4) Priming memory, which is the improved delivery of unconscious perceptions' recognition. 5) Procedural memory, which is our unconscious memory and contains motoric skills and routine acts. The content of this kind of memory cannot be verbalized, and any effort to verbalize it (that is, the explicit awareness of the course of such an action) can disrupt its smooth execution. The storage process is the formation of associations between learning impulses and the long-term memory contents. For instance, the organization of a complex material makes its storage simpler. Grouping a vocabulary using certain criteria with regard to its content or phonetics can also help. There are similar options for the recalling process, reducing its demands and using external impulses-guidelines, which may be verbal or visual. The limbic system structures (with most important among them, the amygdala and the hippocampus) as well as the cortex structures play a decisive part in the storage and consolidation of episodic and semantic content.

\section{Conclusion}

The neuron-scientific research of memory has led us to certain findings which we can use to create guidelines for the successful structuring of school earning and learning motivation. Our goal is to create the proper learning states, properly adjusted to the learning brain. If we seek better learning performance and material assimilation, we should discern among the reductions of memorization demands and strategies for a focused increase in producing memory performance. At the beginning of a teaching session, the teacher should proceed to certain actions, serving different operations: firstly, to prepare his/her students for the imminent material content, in the form of priming (unconscious processing, which should later lead to optimal identification delivery) and secondly, to utilize the students' expectations with regard to the structure of 
a learning session as an external assistant in the organization of the material content. These organizing aspects may also be used subsequently, as impulses-guidelines. When presenting new material content, the teacher should create correlations to the topics already processed with the students. Correlation with already processed topics may also be achieved by working in small groups. The learning state of small groups is a distinct episode, the context of which may assist in recalling. The use of various means (table, film abstracts, presentation of experiments) particularly when commenting on the purpose of their use in class, may help allow the creation of a coherent episode. Distinct episodes increase learning motivation. Content in which the student can identify a personal relationship, an interest of his/her own or an element relative in his/her daily life, can be processed more deeply than content without any subjective importance. When the individual is involved personally, the limbic system structures are activated and allow us a deeper processing of content. The teacher's presence is also very important. Conscious and unconscious enthusiasm exhibited by the teacher about the content he/she is trying to convey, may positively affect the student's motivation for learning. Positive emotions during class-however platitudinous this may seem-not only excite students, but serve as guidelines for activating the brain's rewarding system, which positively affects individuals' behaviors.

\section{References}

Arnold, M. B. (1960). Emotion and Personality. Psychological Aspects, Vol. 1. New York: Columbia University Press.

Atkinson, J. W. (1964). An Introduction to Motivation. New York: Litton Educational Publishing.

Atkinson, R. C., \& Shiffrin, R. M. (1968). Human Memory: A Proposed System and Its Control Processes. In K. W. Spence, \& J. T. Spence (Eds.), The Psychology of Learning and Motivation: Advances in Research and Theory (Vol. 2, pp. 89-195). New York: Academic Press. http://dx.doi.org/10.1016/s0079-7421(08)60422-3

Azrin, N. H., \& Holz, W. C. (1966). Punishment. In W. K. Honig (Ed.), Operant Behavior: Areas of Research and Application (pp. 213-270). New York: Appleton-Century-Crofts.

Baddeley, A. D., \& Hitch, G. J. (1974). Working Memory. In G. A. Bower (Ed.), Recent Advances in Learning and Motivation (Vol. 8, pp. 47-89). New York: Academic Press. http://dx.doi.org/10.1016/s0079-7421(08)60452-1

Bailey, D., Bruer, J., Symons, F., \& Lichtman, J. (2001). Critical Thinking about Critical Periods. Baltimore, ML: Paul H. Brooks Publishing Co.

Bandura, A. (1976). Lernen am Modell. Ansätze zu einer sozial-kognitiven Lerntheorie. Stuttgart: Klett.

Bauer, J. (2009). Kleine Zellen, große Gefühle-wie Spiegelneurone funktionieren. Die neurobiologischen Grundlagen der "Theory of Mind”. In Hermann, U. (Ed.), Neurodidaktik. Grundlagen und Vorschläge für gehirngerechtes Lehren und Lernen (2nd ed., pp. 49-57). Weinheim \& Basel: Beltz Verlag.

Brown, R., \& Kulik, J. (1977). Flashbulb Memories. Cognition, 5, 73-99.

http://dx.doi.org/10.1016/0010-0277(77)90018-X

Cannon, W. B. (1927). The James-Lange Theory of Emotions: A Critical Examination and an Al- 
ternative Theory. The American Journal of Psychology, 39, 106-124.

http://dx.doi.org/10.2307/1415404

Cosmides, L., \& Tooby, J. (2000). Evolutionary Psychology and the Emotions. In M. Lewis, \& J. M. Haviland-Jones (Eds.), Handbook of Emotions (2nd ed., pp. 91-115). New York: Guilford.

Damasio, A. R. (1994). Descartes' Irrtum-Fühlen, Denken und das menschliche Gehirn. München: List.

Ekman, P. (1972). Universals and Cultural Differences in Facial Expressions of Emotion. In J. Cole (Ed.), Nebraska Symposium on Motivation (Vol. 19, pp. 207-282). Lincoln, NE: University of Nebraska Press.

Fazio, R. H. (2001). On the Automatic Activation of Associated Evaluations. An Overview. Cognition \& Emotion, 15, 115-141. http://dx.doi.org/10.1080/02699930125908

Fodor, J. (1983). The Modularity of Mind. Cambridge: MIT Press.

Fridlund, A. J. (1991). The Sociality of Solitary Smiles: Effects of an Implicit Audience. Journal of Personality and Social Psychology, 60, 229-240. http://dx.doi.org/10.1037/0022-3514.60.2.229

Gollwitzer, P. M. (1999). Implementation Intentions: Strong Effects of Simple Plans. American Psychologist, 54, 493-503. http://dx.doi.org/10.1037/0003-066X.54.7.493

Heider, F. (1975). Psychologie der interpersonalen Beziehungen. Stuttgart: Klett.

Hermann, U. (2008). Lernen-Vom Gehirn aus betrachtet. Wie schulisches Lernen verbessert werden kann: Neurowissenschaften und Pädagogik auf dem gemeinsamen Weg zur Neurodida-ktik. http://www.spektrum.de

Heckhausen, H., \& Gollwitzer, P. M. (1987). Thought Contents and Cognitive Functioning in Motivational versus Volitional States of Mind. Motivation \& Emotion, 11, 101-120.

http://dx.doi.org/10.1007/BF00992338

Hoppe, F. (1931). Erfolg und Mißerfolg. Psychologie Forschung, 14, 1-62. http://dx.doi.org/10.1007/BF00403870

Horstmann, G., \& Dreisbach, G. (2012). Allgemeine Psychologie 2 kompakt: Lernen, Emotion, Motivation, Gedächtnis. Weinheim: Beltz Verlag.

Hull, C. L. (1943). Principles of Behavior: An Introduction to Behavior Theory. New York: Appleton-Century-Crofts.

Hüther, G. (2009). Die Bedeutung sozialer Erfahrungen für die Strukturierung des menschlichen Gehirns. Welche sozialen Beziehungen brauchen Schüler und Lehrer? In U. Hermann (Ed.), Neurodidaktik. Grundlagen und Vorschläge für gehirngerechtes Lehren und Lernen (2th ed., pp. 41-48). Weinheim: Beltz Verlag.

Isen, A. M. (1999). Positive Affect. In T. Dalgleish, \& M. J. Power (Eds.), Handbook of Cognition and Emotion (pp. 521-539). Chichester: John Wiley \& Sons Ltd.

http://dx.doi.org/10.1002/0470013494.ch25

James, W. (1884). What Is an Emotion? Mind, 9, 188-295.

http://dx.doi.org/10.1093/mind/os-IX.34.188

Jones, M. C. (1924). A B1 Laboratory Study of Fear: The Case of Peter. Pedagogical Seminary, 31, 308-315. http://dx.doi.org/10.1080/08856559.1924.9944851

Kamin, L. J. (1969). Predictability, Surprise, Attention, and Conditioning. In B. A. Campbell, \& R. M. Church (Eds.), Punishment Aversive Behavior (pp. 279-296). New York: AppletonCentury-Crofts.

Kuhl, J., \& Goschke, T. (1994). A Theory of Action Control: Mental Subsystems, Modes of Control, and Volitional Conflict-Resolution Strategies. In J. Kuhl, \& J. Beckmann (Eds.), Volition and Personality: Action Versus State Orientation (pp. 93-124). Göttingen: Hogrefe. 
Lang, P. J., Bradley, M. M., \& Cuthbert, B. N. (2008). International Affective Picture System (IAPS): Affective Ratings of Pictures and Instruction Manual. Technical Report A-8. Gainesville, FL: University of Florida.

Lazarus, R. S. (1991). Emotion und Adaptation. New York: Oxford University Press.

LeDoux, J. E. (1998). The Emotional Brain: The Mysterious Underpinnings of Emotional Life. New York: Simon \& Schuster.

Levey, A. B., \& Martin, I. (1975). Classical Conditioning of Human Evaluative Responses. Behavioral Research \& Therapy, 13, 221-226. http://dx.doi.org/10.1016/0005-7967(75)90026-1

Lewin, K. (1964). Die Psychologische Situation bei Lohn und Strafe. Darmstadt: Wissenschaftliche Buchgesellschaft.

Markowitsch, H. J. (2002). Dem Gedächtnis auf der Spur. Vom Erinnern und Vergessen. Darmstadt: Wissenschaftliche Buchgesellschaft.

Miller, G. A. (1956). The Magical Number Seven, plus or minus Two: Some Limits on our Capacity for Processing Information. Psychological Review, 63, 81-97.

http://dx.doi.org/10.1037/h0043158

Morris, C. D., Bransford, J. D., \& Franks, J. J. (1997). Levels of Processing versus Transfer Appropriate Processing. Journal of Verbal Learning and Verbal Behavior, 16, 519-533. http://dx.doi.org/10.1016/S0022-5371(77)80016-9

Murray, H. A. (1938). Explorations in Personality. New York: Oxford University Press.

Ortony, A., Clore, G., \& Collins, A. (1988). The Cognitive Structure of Emotions. Cambridge: Cambridge University Press. http://dx.doi.org/10.1017/CBO9780511571299

Premack, D. (1963). Rate Differential Reinforcement in Monkey Manipulation. Journal for the Experimental Analysis of Behavior, 6, 81-89. http://dx.doi.org/10.1901/jeab.1963.6-81

Prinz, W. (2005). An Ideomotor Approach to Imitation. In S. Hurley, \& N. Chater (Eds.), Perspectives on Imitation: From Neuroscience to Social Science (pp. 141-156). Cambridge: Bradford.

Recorla, R. A., \& Wagner, A. R. (1972). A Theory of Pavlovian Conditioning: Variations in the Effectiveness of Reinforcement and Nonreinforcement. In A. H. Black, \& W. F. Prokasy (Eds.), Classical Conditioning II: Current Research and Theory (pp. 64-99). New York: AppletonCentury-Crofts.

Roth, G. (2003). Fühlen, Denken Handeln. Frankfurt Am: Suhrkamp.

Roth, G. (2009). Warum sind Lehren und Lernen so schwierig? In U. Hermann (Ed.), Neurodidaktik. Grundlagen und Vorschläge für gehirngerechtes Lehren und Lernen (2th ed., pp. 58-68). Weinheim: Beltz Verlag.

Russell, J. A. (1991). In Defense of a Prototype Approach to Emotion Concepts. Journal of Personality and Social Psychology, 60, 37-47. http://dx.doi.org/10.1037/0022-3514.60.1.37

Sachser, N. (2009). Neugier, Spiel und Lernen: Verhaltensbiologische Anmerkungen zur Kindheit. In U. Hermann (Ed.), Neurodidaktik. Grundlagen und Vorschläge für gehirngerechtes Lehren und Lernen (2th ed., pp. 19-30). Weinheim: Beltz Verlag.

Schacter, D. L., Chiao, J. Y., \& Mitchell, J. P. (2003). The Seven Sins of Memory: Implications for the Self. In J. LeDoux, J. Debiece, \& H. Moos (Eds.), The Self: From Soul to Brain (Annals of the New York Academy of Sciences Vol. 1001) (pp. 226-239). New York: New York Academy of Sciences.

Seligman, M. E. P. (1970). On the Generality of the Laws of Learning. Psychological Review, 77, 406-418. http://dx.doi.org/10.1037/h0029790

Skinner, B. F. (1963). Operant Behavior. American Psychologist, 18, 503-515. 
http://dx.doi.org/10.1037/h0045185

Slamecka, N. J., \& Graf, P. (1978). The Generation Effect: Delineation of a Phenomenon. Journal of Experimental Psychology: Human Learning and Memory, 4, 592-604.

http://dx.doi.org/10.1037/0278-7393.4.6.592

Spence, K. W. (1958). A Theory of Emotionally Based Drive (D) and Its Relation to Performance in Simple Learning Situations. American Psychologist, 13, 131-141.

http://dx.doi.org/10.1037/h0045054

Sperling, G. (1960). The Information Available in Brief Visual Presentations. Psychological Monographs, 74, 1-29. http://dx.doi.org/10.1037/h0093759

Tulving, E. (2002). Episodic Memory: From Mind to Brain. Annual Reviews of Psychology, 53, 125. http://dx.doi.org/10.1146/annurev.psych.53.100901.135114

Weiner, B. (1980). Human Motivation. New York: Holt.

Wundt, W. (1922). Vorlesungen über die Menschen und Tierseele (7th ed.). Leipzig: Voss.

Submit or recommend next manuscript to SCIRP and we will provide best service for you:

Accepting pre-submission inquiries through Email, Facebook, LinkedIn, Twitter, etc. A wide selection of journals (inclusive of 9 subjects, more than 200 journals)

Providing 24-hour high-quality service

User-friendly online submission system

Fair and swift peer-review system

Efficient typesetting and proofreading procedure

Display of the result of downloads and visits, as well as the number of cited articles

Maximum dissemination of your research work

Submit your manuscript at: http://papersubmission.scirp.org/

Or contact ce@scirp.org 